This manuscript has been authored by UT-Battelle, LLC under Contract No. DE-AC05-000R22725 with the U.S. Department of Energy. The United States Government retains and the publisher, by accepting the article for publication, acknowledges that the United States Government retains a non-exclusive, paid-up, irrevocable, world-wide license to publish or reproduce the published form of this manuscript, or allow others to do so, for United States Government purposes. The Department of Energy will provide public access to these results of federally sponsored research in accordance with the DOE Public Access Plan (http://energy.gov/downloads/doe-public-access-plan).

\title{
Importance of Doping and Frustration in Itinerant Fe-doped $\mathrm{Cr}_{2} \mathrm{Al}$
}

\author{
M.A. Susner ${ }^{*}$ D.S. Parker, and A. S. Sefat \\ Materials Science and Technology Division, Oak Ridge National Laboratory, Oak Ridge, TN \\ 37831-6114 USA
}

susnerma@ornl.gov / mike.susner@gmail.com

\begin{abstract}
We have performed an experimental and theoretical study comparing the effects of $\mathrm{Fe}$-doping of $\mathrm{Cr}_{2} \mathrm{Al}$, an antiferromagnet with a Néel temperature of $670 \mathrm{~K}$, with known results on $\mathrm{Fe}$-doping of antiferromagnetic bcc $\mathrm{Cr}$. $\left(\mathrm{Cr}_{1-x} \mathrm{Fe}_{\mathrm{x}}\right)_{2} \mathrm{Al}$ materials are found to exhibit a rapid suppression of antiferromagnetic order with the presence of $\mathrm{Fe}$, decreasing $T_{N}$ to $\approx 170 \mathrm{~K}$ for $x=0.10$. Antiferromagnetic behavior disappears entirely at $x \approx 0.125$ after which point increasing paramagnetic behavior is exhibited. This is unlike the effects of $\mathrm{Fe}$ doping of bcc antiferromagnetic $\mathrm{Cr}$, in which $T_{N}$ gradually decreases followed by the appearance of a ferromagnetic state. Theoretical calculations explain that the $\mathrm{Cr}_{2} \mathrm{Al}-\mathrm{Fe}$ suppression of magnetic order originates from two causes: the first is band narrowing caused by doping of additional electrons from $\mathrm{Fe}$ substitution that weakens itinerant magnetism; the second is magnetic frustration of the $\mathrm{Cr}$ itinerant moments in Fe-substituted $\mathrm{Cr}_{2} \mathrm{Al}$. In pure-phase $\mathrm{Cr}_{2} \mathrm{Al}$, the $\mathrm{Cr}$ moments have an antiparallel alignment; however, these are destroyed through $\mathrm{Fe}$ substitution and the preference of $\mathrm{Fe}$ for parallel alignment with $\mathrm{Cr}$. This is unlike bulk Fe-doped $\mathrm{Cr}$ alloys in which the Fe anti-aligns with the $\mathrm{Cr}$ atoms, and speaks to the importance of the $\mathrm{Al}$ atoms in the magnetic structure of $\mathrm{Cr}_{2} \mathrm{Al}$ and $\mathrm{Fe}$-doped $\mathrm{Cr}_{2} \mathrm{Al}$.
\end{abstract}

Keywords: Antiferromagnetic Ordering, Magnetic Frustration, $\mathrm{Cr}_{2} \mathrm{Al}$

* Author to whom correspondence should be addressed. 


\section{Introduction}

Magnetism in alloys, particularly those containing iron, has attracted much attention over the past several decades, perhaps in part motivated by the tremendous practical and engineering importance of such materials. One particular alloy system fairly well-studied is that of $\mathrm{Fe}-\mathrm{Cr}$ as these alloys find numerous applications in the production of corrosion-resistant stainless steels [1], nuclear reactor containment vessels [2], and corrosion protection coatings [3]. However, most of these studies have been confined to the Fe-rich part of the phase diagram since these compositions represent the operational range of most applications. Less well-studied, though reasonably well-understood, are the features of the Cr-rich part of the phase diagram, particularly with respect to magnetic behavior. Cr alloys and compounds in particular have sparked recent interest as 3-D structured materials such as CrAs have been shown to exhibit superconductivity under pressure [4-6]. Given that a feature common to unconventional superconducting systems is the emergence of superconducting behavior from a long-range antiferromagnetically (AF) ordered state, it is imperative that these AF interactions are well-understood.

As is well-known, body-centered cubic (bcc) $\mathrm{Cr}$ is an itinerant antiferromagnet with a Néel temperature $\left(T_{N}\right)$ of $312 \mathrm{~K}$ [7] with an incommensurate spin-density wave forming on the background of the AF state. The effects on the AF state with respect to alloying $\mathrm{Cr}$ with $\mathrm{Fe}$ has been the subject of some investigation which we now briefly summarize. In an early study, Mitchell and Goff [8] studied the depression of the $T_{N}$ through doping $\mathrm{Cr}$ with Fe, finding that this rate was similar to that of Mo doping, which is perhaps surprising considering the magnetic character of Fe. A somewhat more recent study by Moze et al. [9] examined highly dilute (<5 at. \% Fe) alloys, finding an ordered moment on the Fe-site with little effect on the Cr atoms, a result we corroborate below. With respect to theory, an early work by Kakehashi [10] found that Fe substitution led to a loss of local moment on the Cr site in contrast to the aforementioned experimental results of Moze et al. [9]. In a more recent theory-based investigation, Klaver et al. [11] reported a somewhat variable but significant Fe moment on the Cr-rich side of the phase diagram. These works generally find that $\mathrm{Fe}$ atoms embedded within the $\mathrm{Cr}$ bcc structure carry a sizable local moment, with the $T_{N}$ decreasing gradually as the Fe content increases (i.e. $\sim 10 \mathrm{~K}$ per atomic percent 
Fe [8]). Ultimately, the material transitions to a ferromagnetic state for Fe concentrations above about 20\%. In this work we shall discuss experimental and theoretical findings on the Fe-alloyed $\mathrm{Cr}_{2} \mathrm{Al}$ system that would naturally be expected to show similar response. However, the behavior exhibited by $\mathrm{Cr}_{2} \mathrm{Al}$ is radically different from $\mathrm{Cr}$. While $\mathrm{Cr}_{2} \mathrm{Al}$ is indeed an itinerant antiferromagnet like bcc $\mathrm{Cr}$, we find that alloying with Fe produces a much more rapid decrease of $T_{N}$ of approximately $50 \mathrm{~K}$ per percent $\mathrm{Fe}$ added. Additionally, no magnetism is present in $\left(\mathrm{Cr}_{1-\mathrm{x}} \mathrm{Fe}_{\mathrm{x}}\right)_{2} \mathrm{Al}$ from above $x=0.125$ up to $x=0.500$. We find that we can explain these interesting behaviors in terms of a combination of two factors: charge doping with additional electrons and magnetic frustration, a feature of less prominence in the aforementioned dilute Fe-Cr system.

As depicted in Figure 1, $\mathrm{Cr}_{2} \mathrm{Al}$ crystallizes in a tetragonal $\mathrm{MoSi}_{2}$-type structure (space group 139). It exhibits antiferromagnetic behavior with a $T_{N}$ of approximately $670 \mathrm{~K}$ [12-14]. Each $\mathrm{Cr} 1$ atom is nearest-neighbor coordinated with 4 other $\mathrm{Cr}$ atoms arranged in a square, centered and vertically displaced with respect to atom $\mathrm{Cr} 1$. The shortest distance between $\mathrm{Cr}$ atoms in $\mathrm{Cr}_{2} \mathrm{Al}$ is from $\mathrm{Cr} 1-\mathrm{Cr} 2$ $(2.433 \AA$ ), while the next nearest neighbor distance is from $\mathrm{Cr} 2$ to $\mathrm{Cr} 2$ ' at $2.99 \AA$ (cf. the $a$ and $b$ lattice parameters). The structure thus can be described as four $\mathrm{Cr}$ planes interpenetrating a body-centered tetragonal $\mathrm{Al}$ lattice with two planes located on either side of the body-centered atom. The inner Cr planes have their atomic positions in registry with the corner $\mathrm{Al}$ atoms while the outer $\mathrm{Cr}$ planes have their atomic positions aligned with the body-centered $\mathrm{Al}$ atoms. Even though the $\mathrm{Al}$ atoms play an important structural role, one might expect them to have little effect on the magnetism of the compound. Below we shall see that this is in fact not the case.

The antiferromagnetic ground state of $\mathrm{Cr}_{2} \mathrm{Al}$, as experimentally determined by Atoji [12] and Kallel and Debergev [13] and later confirmed by our first principles density functional theory calculations (below), can be described as ferromagnetic alignment within the $\mathrm{Cr}$ planes (i.e. next-nearest Cr neighbors) and an antiferromagnetic alignment between adjacent planes (i.e. nearest $\mathrm{Cr}$ neighbors). This behavior follows the pattern of magnetic interactions becoming more ferromagnetic for transition 
group metals as the distance between $3 d$ elements is increased. Neutron diffraction experiments (Ref. [12]) show that canted spins are aligned $65^{\circ}$ with respect to the $c$ axis, essentially aligned parallel to the direction of the $\mathrm{Cr} 1-\mathrm{Cr} 2$ bond. It was therefore proposed that the antiferromagnetic ordering in $\mathrm{Cr}_{2} \mathrm{Al}$ is a result of the exchange coupling between nearest neighbor $\mathrm{Cr}$ atoms [14]. Indeed, we will see that $\mathrm{Cr}_{2} \mathrm{Al}$ is an itinerant antiferromagnet, as careful theoretical efforts to discern the existence of a ferromagnetically ordered state (including fixed-spin moment calculations) find no such state.

A previous doping study of $\mathrm{Cr}_{2} \mathrm{Al}$ was performed with the substitution of $\mathrm{Fe}$ on the $\mathrm{Cr}$ site [14]. The $\mathrm{MoSi}_{2}$ crystal structure was maintained for a high level of Fe substitution, $\left(\mathrm{Cr}_{0.88} \mathrm{Fe}_{0.12}\right)_{2} \mathrm{Al}$, and the value of $T_{N}$ decreased with increased doping concentration down to $310 \mathrm{~K}$ for the composition $\left(\mathrm{Cr}_{0.925} \mathrm{Fe}_{0.075}\right)_{2} \mathrm{Al}$. Further doping to the composition $\left(\mathrm{Cr}_{0.915} \mathrm{Fe}_{0.085}\right)_{2} \mathrm{Al}$ yielded an ambiguous value for $T_{N}$ in the range 100-300 K. Antiferromagnetic ordering was suppressed altogether for the composition $\left(\mathrm{Cr}_{0.88} \mathrm{Fe}_{0.12}\right)_{2} \mathrm{Al}$. This decrease in $T_{N}$ was ascribed to the increased separation distance between neighboring $\mathrm{Cr}$ planes in the unit cell which in turn reduced the $\mathrm{Cr}-\mathrm{Cr}$ magnetic interactions and the moment they produce [14]. In $\left(\mathrm{Cr}_{1-\mathrm{x}} \mathrm{Fe}_{\mathrm{x}}\right)_{2} \mathrm{Al}$, a factor which has not been considered until now is the interplay of the magnetic energies in the system. The addition of a dopant such as $\mathrm{Fe}$ has been experimentally shown to decrease the average moment on the $\mathrm{Cr} / \mathrm{Fe}$ sites [14]. The extra magnetic energy introduced by the presence of $\mathrm{Fe}$ in the $\mathrm{Cr}_{2} \mathrm{Al}$ structure has been predicted to produce interesting electronic properties once the magnetism in the compound is suppressed. In this report, the magnetic effects resulting from the substitution of $\mathrm{Fe}$ for $\mathrm{Cr}$ are presented in detail. These results are complemented by theory that demonstrates the doping and magnetic frustration-induced suppression of antiferromagnetism with Fe substitution.

\section{Experimental}

The $\left(\mathrm{Cr}_{1-\mathrm{x}} \mathrm{Fe}_{\mathrm{x}}\right)_{2} \mathrm{Al}$ samples with compositions $0 \leq x \leq 0.5$ were synthesized from high purity elements (all 99.996\% or greater) purchased from Alfa Aesar, Inc. The constituent elements were arcmelted under Ar atmosphere, placed in alumina crucibles, sealed in a partially evacuated silica ampoule, 
and annealed for $48-72$ hours at $1050^{\circ} \mathrm{C}$. Table I lists all compositions and heat-treatments used in this investigation.

Structural characterization of the compositions was done using a PANalytical X'Pert Pro MPD X-ray powder diffractometer. The X-ray apparatus uses Ni-filtered $\mathrm{Cu} K_{\alpha}$ radiation; the solid state detector has a $2.122^{\circ}$ active length. All scans were collected from $5-90^{\circ} 2 \theta$ for 40 minutes. PANalytical HighScore-Plus software was used for phase identification. Impurities were less than $5 \%$ by mass for each of the samples. Rietveld refinements were performed using FullProf 2.05 [15] and typically resulted in $R_{w p}$ values of $\sim 6.3-7.3$ with $R_{\exp }$ values of $\sim 5.2-5.7$; a typical refinement is shown in Figure 1a and the final results are presented in Table I.

The temperature-dependent resistance was measured using a Quantum Design Physical Property Measurement System (PPMS) on specimens cut from the arc-melted and annealed ingots. The temperature sweeps $(<2 \mathrm{~K} / \mathrm{min})$ were in the range of $5-400 \mathrm{~K}$. All compositions showed metallic behavior where $\rho(T)$ follows a $T^{3}$ dependence. The value of $\rho_{300 \mathrm{~K}}$ generally increased with doping, following Nordheim's rule for alloying [16].

The dc magnetization as a function of temperature was measured using a Quantum Design Magnetic Properties Measurement System (MPMS) SQUID magnetometer; the oven option was used to access temperatures above $400 \mathrm{~K}$. Typically, the samples were cooled to $5 \mathrm{~K}$ after which point the magnetic field was applied (either $10^{3}$ or $10^{4}$ Oe) and data collected upon warming (zfc). For paramagnetic samples, the data were fitted to the modified Curie-Weiss law, $M / H=\chi=\mathrm{C} /(T-\theta)+\chi_{0}$, where $\chi$ is magnetic susceptibility, $C$ is Curie constant, $\theta$ is Weiss temperature, and $\chi_{0}$ is a temperatureindependent term that includes contributions from Pauli and van Vleck paramagnetism and Landau diamagnetism. The fits applied above $100 \mathrm{~K}$ are presented in Table II together with the estimation of effective moment, $\mu_{\text {eff }}$, extracted using the relation $\mu_{e f f}=\left(3 C k_{B} / N_{A}\right)^{1 / 2}$, where $k_{B}$ and $N_{A}$ are the Boltzmann and Avogadro constants, respectively [17]. 


\section{Experimental Results}

In Figure 1a we present a typical XRD plot measured for the $\left(\mathrm{Cr}_{1-\mathrm{x}} \mathrm{Fe}_{\mathrm{x}}\right)_{2} \mathrm{Al}$ system for $x=0$. It refines with tetragonal space group I4/mmm (No. 139), presented pictorially in Figure 1d. The changes in the positions of the (200) and (213) reflections with increased Fe concentration are highlighted in Figures $1 \mathrm{~b}$ and 1c. The refinements of the XRD patterns that detail these changes are presented in Table I. As more $\mathrm{Fe}$ is substituted for $\mathrm{Cr}$, the $a$ and $b$ lattice parameters contract while $c$ elongates. In Figure 2 the evolution of the refined lattice parameters with Fe content are presented. As c/a approaches 3 between $x=0.2$ and $x=0.25$, the unit cell is better described by the bcc crystal structure $\left(R_{w p} / R_{e x p}=1.01\right)$ than by the $\mathrm{MoSi}_{2}$ structure $\left(R_{w p} / R_{\text {exp }}=1.39\right)$. This is true for both $\left(\mathrm{Cr}_{0.75} \mathrm{Fe}_{0.25}\right)_{2} \mathrm{Al}$ and $\left(\mathrm{Cr}_{0.5} \mathrm{Fe}_{0.5}\right)_{2} \mathrm{Al}$ compositions. This result is not necessarily surprising given the high propensity of both $\mathrm{Cr}$ and $\mathrm{Fe}$ to form bec solid solutions with $\mathrm{Al}$, particularly at higher temperatures [18-22]. What is surprising is the retention of a single phase upon cooling to room temperature. Though the full ternary system is well-reported at higher temperatures, there is little information present in the literature relating to temperatures below $600^{\circ} \mathrm{C}$ [23]. From the $600^{\circ} \mathrm{C}$ phase diagram, however, it is predicted for this composition that two phases will form from a high temperature solid solution of $\mathrm{Cr}, \mathrm{Fe}$, and $\mathrm{Al}-\mathrm{Cr}_{2} \mathrm{Al}$ and a bcc solid solution of $\mathrm{Cr}, \mathrm{Al}$, and Fe. The presence of a single phase suggests that the phase diagram for the ternary Cr-Fe-Al system needs some reevaluation.

The temperature-dependence of magnetic susceptibility is plotted in Figure 3. The inset of the same figure presents the evolution of the antiferromagnetic transition temperature with increased $x$. Table II lists the value of $T_{N}$ and the resulting fits and analyses using the modified Curie-Weiss function. The parent $\mathrm{Cr}_{2} \mathrm{Al}$ has a $T_{N}=670(8) \mathrm{K}$, in accord with the previously reported value of $663 \mathrm{~K}$ [14]. With the addition of a very small quantity of $\mathrm{Fe}$ (i.e. for the composition $\left.\left(\mathrm{Cr}_{0.975} \mathrm{Fe}_{0.025}\right)_{2} \mathrm{Al}\right)$, the value of $T_{N}$ falls to $\approx 565 \mathrm{~K}$ (Table II). Further increases in doping concomitantly decrease $T_{N}$ until there is no apparent antiferromagnetic transition above $5 \mathrm{~K}$ at the composition $\left(\mathrm{Cr}_{0.875} \mathrm{Fe}_{0.125}\right)_{2} \mathrm{Al}$. 
In Figure 3 it is also shown that as Fe concentration increases to $x=0.125$ and beyond, the samples become increasingly paramagnetic. Referring to the results from the Curie-Weiss listed in Table II, it is evident that the effective magnetic moment per $\mathrm{Cr} / \mathrm{Fe}$ (i.e. transition metal element or $\mathrm{TM}$ ) increases from $\approx 0$ for $\left(\mathrm{Cr}_{0.875} \mathrm{Fe}_{0.125}\right)_{2} \mathrm{Al}$, to $0.39(3) \mu_{B} / \mathrm{TM}$ for $\left(\mathrm{Cr}_{0.5} \mathrm{Fe}_{0.5}\right)_{2} \mathrm{Al}$. It is interesting that the system continues with metallic behavior as gauged by resistive measurements even though $\mu_{e f f}$ is increasing so dramatically. From the same Curie-Weiss fits, we note that the values of $\theta$ become less negative with $x$, behavior which accents the diminishing of long-range antiferromagnetic interactions induced by $\mathrm{Fe}$ substitution. No other magnetic ordering is exhibited. The resulting magnetic phase diagram of the $\left(\mathrm{Cr}_{1-}\right.$ $\left.{ }_{\mathrm{x}} \mathrm{Fe}_{\mathrm{x}}\right)_{2} \mathrm{Al}$ system is plotted in Figure 4 and includes our experimentally obtained values of $T_{N}$ and $\mu_{e f f}$. The data from previous works [14] which include $T_{N}$ and the values of the ordered moments, $\mu$, from neutron diffraction experiments at $1.5-4.2 \mathrm{~K}$ are also included for completeness. We find that the antiferromagnetic region lies between $x=0$ and $x=0.125$, after which point the system shifts to paramagnetic behavior. It is quite surprising that $\mathrm{Fe}$ does not make a greater contribution to the formation of a new magnetic phase once the antiferromagnetic ordering of the parent $\mathrm{Cr}_{2} \mathrm{Al}$ is suppressed, as is found in similar alloys [24]. The principal goal of the next section of this paper is to explain this unexpected behavior.

\section{Discussion}

In order to understand why antiferromagnetic $\mathrm{Cr}_{2} \mathrm{Al}$ that is doped with ferromagnetic $\mathrm{Fe}$ generates a non-magnetic ground state, we have performed first principles density functional theory calculations on $\mathrm{Cr}_{2} \mathrm{Al}$ using the linearized augmented planewave all-electron code WIEN2K [25] and compared these findings with results from the same analysis performed on $\mathrm{Cr}-\mathrm{Fe}$ alloys. In performing our calculations we have used the generalized gradient approximation of Perdew, Burke and Ernzerhof [26] throughout with well-converged basis sets $\left(R K_{\max }=9.0\right.$, where $R$ is the smallest sphere radius and $K$ is the magnitude of the largest planewave vector) for all calculations. 
We calculated the experimentally-determined antiferromagnetic (AF) ground state (cf. Fig. 1d) in which neighboring nearest-neighbor $\mathrm{Cr}$ planes are antiferromagnetically aligned and ferromagnetic alignment is present within the Cr planes. In addition, we have conducted fixed-spin moment calculations to search for a possible ferromagnetic state. No such ferromagnetic state was found; indeed, the calculated energy increased monotonically from the AF value as the moment was increased such that the magnetism in $\mathrm{Cr}_{2} \mathrm{Al}$ can clearly be described as itinerant, and the energy of the AF state relative to a non-spinpolarized (NSP) state is reflective of the actual ordering energy of the system. This is unlike local moment formation, in which the actual ordering energy is much less than the energy difference of AF and NSP states. In this case we find an actual ordering energy of $560 \mathrm{~K} / \mathrm{Cr}$, which agrees relatively well with the experimental $T_{N}$ of $\approx 670 \mathrm{~K}$. For comparison, we performed analogous calculations for a nearest neighbor AF state in bcc Cr. As with $\mathrm{Cr}_{2} \mathrm{Al}$, we find this to be an itinerant state, with a substantially lower ordering energy of $276 \mathrm{~K} / \mathrm{Cr}$, again in good agreement with the experimental $T_{N}$ of bcc $\mathrm{Cr}$ of $313 \mathrm{~K}$. We have not attempted to model the actual spin-density-wave ground-state of $\mathrm{Cr}$, but note that this effect is a relatively small one and seems to have comparatively little impact on the effect of Fe alloying.

Next, to study the effects of Fe alloying in these two systems, we have performed calculations within the virtual crystal approximation. Here we have added electrons to simulate the effect of Fe addition. In addition, we have performed supercell calculations in which one of the four equivalent $\mathrm{Cr}$ atoms is substituted by a Fe atom (we considered a $2 \times 2 \times 2$ supercell of bcc $\mathrm{Cr}$, which as an fcc structure has $4 \mathrm{Cr}$ sites in the Wigner-Seitz primitive cell). While this situation represents a somewhat higher Fe concentration than those at which the $\mathrm{Cr}_{2} \mathrm{Al}-\mathrm{Fe}$ alloy remains antiferromagnetic, the results of this calculation provide much useful insight into the origin of these disparate behaviors.

For virtual crystal approximation (VCA) calculations, depicted in Table III are the ordering energies for a series of $\left(\mathrm{Cr}_{1-\mathrm{x}} \mathrm{Fe}_{\mathrm{x}}\right)_{2} \mathrm{Al}$ and $\mathrm{Cr}_{1-\mathrm{x}} \mathrm{Fe}_{\mathrm{x}}$ alloys, with the experimental antiferromagnetic order assumed for both cases. The table shows a rapid reduction in ordering energies with charge doping for the $\left(\mathrm{Cr}_{1-\mathrm{x}} \mathrm{Fe}_{\mathrm{x}}\right)_{2} \mathrm{Al}$ series, but no such effect for $\mathrm{Cr}_{1-\mathrm{x}} \mathrm{Fe}_{\mathrm{x}}$. In fact, for this material, the ordering energy actually 
increases with $x$. This is consistent with a large local moment energy created by the additional charge as a means of simulating Fe alloying.

For our purposes, it is illustrative to consider a comparison between these calculations. Fig. 5 presents three densities-of-states (DOS) studied within VCA: pure metallic $\mathrm{Cr}, \mathrm{Cr}_{2} \mathrm{Al}$, and $\left(\mathrm{Cr}_{0.75} \mathrm{Fe}_{0.25}\right)_{2} \mathrm{Al}$; we plot the non-spin-polarized DOS for clarity since the effects are evident in these. With the exception of a likely Van Hove singularity [27] in the pure Cr DOS at approximately $1.5 \mathrm{eV}$ above the Fermi energy, the plots exhibit, at first glance, comparatively similar behavior. A more careful observation, however, finds important differences. The middle plot of non-magnetic $\mathrm{Cr}_{2} \mathrm{Al}$ shows significantly wider bands than the pure $\mathrm{Cr}$ plot, with regions of significant DOS even $5 \mathrm{eV}$ above the Fermi energy. This is consistent with our finding of $\mathrm{Cr}_{2} \mathrm{Al}$ as an itinerant antiferromagnet; accordingly, the $T_{N}$ of $670 \mathrm{~K}$ is much higher than the $311 \mathrm{~K}$ value for pure $\mathrm{Cr}$. Upon doping with $\mathrm{Fe}$, however, the bands become significantly narrower. For example, the broad maximum centered at $1.75 \mathrm{eV}$ above the Fermi energy in $\mathrm{Cr}_{2} \mathrm{Al}$ moves to $1 \mathrm{eV}$ in the VCA plot. Some, but not all, of this shift is attributable to a rigid-band-like effect motion of the bands relative to $E_{F}$ with doping; however, the narrowing of the bands with doping is characteristic of weakening magnetism in an itinerant system. Accordingly, the VCA calculation, when performed as a spin-polarized calculation, converges to a non-spin polarized result which is indicative of a lack of magnetism in $\left(\mathrm{Cr}_{0.75} \mathrm{Fe}_{0.25}\right)_{2} \mathrm{Al}$. This phenomenon is experimentally observed above.

In order to study this result in more detail, as well as check the applicability of the VCA, we performed spin-polarized calculations (including fixed-spin moment, FSM, calculations) of $\left(\mathrm{Cr}_{0.75} \mathrm{Fe}_{0.25}\right)_{2} \mathrm{Al}$ in a cell with $3 \mathrm{Cr}$ and $1 \mathrm{Fe}$ atoms. The ground state is magnetic, but has an observed ordering energy (relative to the non-spin-polarized case) of only $30 \%$ of the value of $\mathrm{Cr}_{2} \mathrm{Al}$. In addition, from the FSM calculations we find at least one metastable solution only $4 \mathrm{meV}$ above the ground state in a different magnetic arrangement. This near-degeneracy of states hints at possible frustration. In fact, in the ground state the Fe prefers to align parallel to its nearest neighbor $\mathrm{Cr}$. This arrangement will tend to 
frustrate the Cr system's desire to order antiferromagnetically because we find that the Fe atoms have a strong tendency, roughly $3000 \mathrm{~K} / \mathrm{Fe}$, to align ferromagnetically when neighbors. This means that any clusters of adjacent Fe (whose frequency increases with the square of the Fe concentration) will cause the surrounding $\mathrm{Cr}$ atoms to tend towards FM order, which will in turn be frustrated by the AF ordering preferred by the Cr. The net result is a highly disordered, degenerate state with $T_{N}$ quickly driven to zero, as observed experimentally.

To demonstrate this quantitatively, in Figure 6 below we present the results of these fixed spin moment calculations for both situations $-\mathrm{Cr}_{3} \mathrm{FeAl}_{2}$ (i.e. $x=0.25$ for $\left(\mathrm{Cr}_{1-x} \mathrm{Fe}_{x}\right) \mathrm{Al}$ ) and $\mathrm{Cr}_{3} \mathrm{Fe}$ (i.e. $x=0.25$ for $\left.\mathrm{Cr}_{1-\mathrm{x}} \mathrm{Fe}_{\mathrm{x}}\right)$. The results demonstrate a radical difference in the behavior of these putatively similar systems. In particular, the base $\mathrm{Cr}_{3} \mathrm{Fe}$ alloy demonstrates a single minimum at a moment value of approximately $0.45 \mu_{\mathrm{B}} / \mathrm{TM}$. From the same figure we readily see that energies rapidly increase away from this point. This means that in this system there is only one stable state. Hence, the system will choose this magnetic state, with robust ordering, as its groundstate. The situation is radically different for $\mathrm{Cr}_{3} \mathrm{FeAl}_{2}$. $\mathrm{This}$ system shows a pair of nearly degenerate minima, only a few meV apart, for moments of approximately $0.23 \mu_{\mathrm{B}}$ and $0.45 \mu_{\mathrm{B}} / \mathrm{TM}$. Hence, at finite temperatures both of these states will be stable and accessible. Since these represent very different configurations, the system will have difficulty choosing an electronic groundstate. Effective frustration will result and the value of $T_{N}$ will be quickly reduced, again as observed in the experimental results.

\section{Conclusions}

A doping investigation of the $\mathrm{Cr}_{2} \mathrm{Al}$ antiferromagnet and a comparative theoretical investigation of Fe alloying of this compound in relation to Fe-alloyed bcc $\mathrm{Cr}$ was carried out. In the experiment, antiferromagnetic ordering was reduced rapidly with $\mathrm{Fe}$ alloying and completely destroyed at the composition $\mathrm{x}=0.125$ with a paramagnetic state prevailing at doping concentrations above this point. Theoretical calculations explain this rapid suppression of magnetism, as well as a lack of magnetism in 
the more heavily alloyed samples, as stemming from a combination of charge doping and magnetic frustration arising from competing near-degenerate states. This is quite unlike the situation in Fe-alloyed $\mathrm{Cr}$, in which local moments develop on the Fe atomic site, the magnetism disappears more slowly with Fe doping, and magnetism transitions directly from antiferromagnetism to weak ferromagnetism.

\section{Acknowledgements}

This work was supported by the Oak Ridge National Laboratory LDRD funding program. A.S. also acknowledges support by the Department of Energy, Office of Basic Energy Sciences, Materials Sciences and Engineering Division. We acknowledge Zachary C. Sims for his assistance in collecting resistivity data. Finally, we give our sincerest thanks to Lisa Zevorich Susner for her assistance in revising the manuscript.

\section{References}

[1] J. Abenojar, F. Velasco, J. M. Torralba, J. A. Bas, J. A. Calero, and R. Marce, Mater. Sci. Eng., A A335, 1 (2002).

[2] A. Y. Churyumov, M. G. Khomutov, A. N. Solonin, A. V. Pozdniakov, T. A. Churyumova, and B. F. Minyaylo, Mater. Des. 74, 44 (2015).

[3] A. Beni, N. Ott, M. Pawelkiewicz, M. Warde, K. Young, B. Bauer, P. Rajput, B. Detlefs, J. Zegenhagen, R. McGrath, M.-G. Barthes-Labrousse, L. P. H. Jeurgens, and P. Schmutz, Electrochem. Commun. 46, 13 (2014).

[4] W. Wu, J. Cheng, K. Matsubayashi, P. Kong, F. Lin, C. Jin, N. Wang, Y. Uwatoko, and J. Luo, Nat Commun 5, (2014).

[5] H. Kotegawa, S. Nakahara, H. Tou, and H. Sugawara, J. Phys. Soc. Jpn. 83, 093702/1 (2014).

[6] L. Keller, J. S. White, M. Frontzek, P. Babkevich, M. A. Susner, Z. C. Sims, A. S. Sefat, H. M. Rønnow, and C. Rüegg, Phys. Rev. B 91, 020409 (2015).

[7] T. M. Rice, A. S. Barker Jr., B. I. Halperin, and D. B. McWhan, J. Appl. Phys. 40, 1337 (1969).

[8] M. A. Mitchell and J. F. Goff, Phys. Rev. B [3]5, 1163 (1972).

[9] O. Moze, P. W. Mitchell, S. K. Burke, J. R. Davis, and J. G. Booth, J. Phys. F: Met. Phys. 18, 527 (1988).

[10] Y. Kakehashi, Phys. Rev. B: Condens. Matter 35, 4973 (1987).

[11] T. P. C. Klaver, R. Drautz, and M. W. Finnis, Phys. Rev. B: Condens. Matter Mater. Phys. 74, 094435/1 (2006).

[12] M. Atoji, Journal of Chemical Physics 43, 222 (1965).

[13] A. Kallel and F. Debergev, Solid State Communications 5, 955 (1967). 
[14] A. Kallel, C. R. Acad. Sci., Paris, Ser. A B 268, 455 (1969).

[15] C. Frontera and J. Rodriguez-Carvajal, Physica B (Amsterdam, Neth.) 350, e731 (2004).

[16] L. Nordheim, Annalen Der Physik 401, 607 (1931).

[17] J. I. Hoppe, J. Chem. Educ. 49, 505 (1972).

[18] N. B. Pugacheva, E. O. Ekzemplyarova, and S. M. Zadvorkin, Metally 68 (2006).

[19] A. M. Van der Kraan and K. H. J. Buschow, Physica B+C (Amsterdam) 138, 55 (1986).

[20] W. Zarek, E. Talik, J. Heimann, M. Kulpa, A. Winiarska, and M. Neumann, J. Alloys Compd. 297, 53 (2000).

[21] M. Palm, J. Alloys Compd. 252, 192 (1997).

[22] N. C. Oforka and C. W. Haworth, Scand. J. Metall. 16, 184 (1987).

[23] G. V. Raynor and V. G. Rivlin, in Phase Equilibria Iron Ternary Alloys (Inst. Met., London, UK, 1988), pp. 81-97.

[24] R. D. Shull, H. Okamoto, and P. A. Beck, Solid State Commun. 20, 863 (1976).

[25] P. Blaha, K. Schwarz, G. K. H. Madsen, D. Kvasnicka, and J. Luitz, WIEN2k, An Augmented Plane Wave + Local Orbitals Program for Calculating Crystal Properties (Techn. Universitat Wien, Vienna, Austria, 2014).

[26] J. P. Perdew, K. Burke, and M. Ernzerhof, Phys. Rev. Lett. 77, 3865 (1996).

[27] L. van Hove, Phys. Rev. 89, 1189 (1953). 


\section{List of Tables}

Table I. Sample compositions and resultant lattice parameter refinements of $\left(\mathrm{Cr}_{1-x} \mathrm{Fe}_{x}\right)_{2} \mathrm{Al}$. For compositions $0 \leq x \leq 0.2$ the structure refines as tetragonal $I 4 / \mathrm{mmm}$; for compositions $x \geq 0.25$ the structure refines as cubic $\operatorname{Im} \overline{3} m$.

Table II. Magnetic properties of $\left(\mathrm{Cr}_{1-x} \mathrm{Fe}_{x}\right)_{2} \mathrm{Al}$ samples; TM: transition metal.

Table III. Comparison of $\left(\mathrm{Cr}_{1-\mathrm{x}} \mathrm{Fe}_{\mathrm{x}}\right)_{2} \mathrm{Al}$ and $\mathrm{Cr}_{1-\mathrm{x}} \mathrm{Fe}_{\mathrm{x}}$ ordering energies, with $x$. 
Table I. Sample compositions and resultant lattice parameter refinements of $\left(\mathrm{Cr}_{1-x} \mathrm{Fe}_{x}\right)_{2} \mathrm{Al}$. For compositions $0 \leq x \leq 0.2$ the structure refines as tetragonal $\mathrm{I} / \mathrm{m} / \mathrm{mmm}$; for compositions $x \geq 0.25$ the structure refines as cubic $\operatorname{Im} \overline{3} m$.

\begin{tabular}{ccccc}
\hline \hline $\boldsymbol{x}$ & $\boldsymbol{a}(\AA)$ & $\boldsymbol{c}(\boldsymbol{\AA})$ & $\boldsymbol{c} \boldsymbol{a}$ & $\boldsymbol{V}\left(\AA^{3}\right)$ \\
\hline 0.00 & $3.0042(2)$ & $8.647(1)$ & 2.878 & $78.04(1)$ \\
0.025 & $3.0016(3)$ & $8.692(1)$ & 2.896 & $78.31(1)$ \\
0.050 & $2.9849(2)$ & $8.699(1)$ & 2.914 & $77.51(1)$ \\
0.075 & $2.9795(4)$ & $8.717(1)$ & 2.926 & $77.38(2)$ \\
0.100 & $2.9735(3)$ & $8.711(1)$ & 2.930 & $77.02(1)$ \\
0.125 & $2.9688(3)$ & $8.716(1)$ & 2.936 & $76.82(1)$ \\
0.150 & $2.9648(3)$ & $8.725(1)$ & 2.943 & $76.69(1)$ \\
0.200 & $2.9542(3)$ & $8.740(1)$ & 2.959 & $76.28(1)$ \\
0.250 & $2.9403(3)$ & - & 1 & $25.420(4)$ \\
0.500 & $2.9069(2)$ & - & 1 & $24.564(3)$ \\
\hline \hline
\end{tabular}


Table II. Magnetic properties of $\left(\mathrm{Cr}_{1-x} \mathrm{Fe}_{x}\right)_{2} \mathrm{Al}$ samples; TM: transition metal

\begin{tabular}{|c|c|c|c|c|c|}
\hline$x$ & $T_{N}(\mathbf{K})$ & $C\left(10^{-3}\right.$ emu $\left.\mathrm{K} \mathrm{mol}^{-1} \mathrm{Oe}^{-1}\right)$ & $\mu_{e f f}\left(\mu_{B} / \mathbf{T M}\right)$ & $\theta(\mathbf{K})$ & $\chi_{0}\left(10^{-4} \mathrm{emu} \mathrm{mol}^{-1} \mathrm{Oe}^{-1}\right)$ \\
\hline 0 & $670(8)$ & -- & -- & -- & -- \\
\hline 0.025 & $565(11)$ & -- & -- & -- & -- \\
\hline 0.050 & $466(15)$ & -- & -- & -- & -- \\
\hline 0.075 & $344(6)$ & -- & -- & -- & -- \\
\hline 0.100 & $170(7)$ & -- & -- & -- & -- \\
\hline 0.125 & -- & $0.43(18)$ & $0.03(6)$ & $-34.4(3)$ & $4.32(5)$ \\
\hline 0.150 & -- & $13.3(6)$ & $0.16(3)$ & $-10.9(3)$ & $4.47(2)$ \\
\hline 0.250 & -- & 26.9(4) & $0.23(2)$ & $-7.2(8)$ & $5.11(1)$ \\
\hline 0.500 & -- & $74.8(4)$ & $0.39(3)$ & $-6.1(3)$ & $6.27(1)$ \\
\hline
\end{tabular}


Table III. Comparison of $\left(\mathrm{Cr}_{1-\mathrm{x}} \mathrm{Fe}_{\mathrm{x}}\right)_{2} \mathrm{Al}$ and $\mathrm{Cr}_{1-\mathrm{x}} \mathrm{Fe}_{\mathrm{x}}$ ordering energies, with $x$.

\begin{tabular}{lll}
\hline \hline$x$ & \multicolumn{2}{l}{ VCA ordering energy/3d $(\mathrm{K})$} \\
$\left(\mathbf{C r}_{\mathbf{1 - \mathbf { x }}} \mathbf{F} \mathbf{e}_{\mathbf{x}}\right)_{\mathbf{2}} \mathbf{A l}$ & $\mathbf{C r}_{\mathbf{1 - \mathbf { x }}} \mathbf{F e}_{\mathbf{x}}$ \\
\hline 0 & 560 & 276 \\
0.025 & 398 & 329 \\
0.05 & 258 & 367 \\
0.075 & 146 & 367 \\
0.10 & 60 & 354 \\
0.125 & $<1$ & 332 \\
\hline \hline
\end{tabular}




\section{List of Figures}

Figure 1. a) XRD pattern of $\left(\mathrm{Cr}_{1-x} \mathrm{Fe}_{x}\right)_{2} \mathrm{Al}, x=0.0$ showing experimental data, Rietveld refinement, and difference plot $\left(R_{w p}=7.30, R_{\text {exp }}=5.71\right)$; b) Expanded view of evolution of (200) peak reflection showing systematic peak shift to larger $2 \theta$ (i.e. smaller $d$ ) with increasing Fe substitution; c) Expanded view of (213) and (116) peak reflections showing the same; d) crystal structure of the parent compound $\mathrm{Cr}_{2} \mathrm{Al}$ with $\mathrm{Cr}-\mathrm{Cr}$ atomic plane separation distance and spin structure adapted from Kallel [14] and Atoji [12].

Figure 2. Evolution of $\left(\mathrm{Cr}_{1-\mathrm{x}} \mathrm{Fe}_{\mathrm{x}}\right)_{2} \mathrm{Al}$ with increasing Fe concentration. The top graph shows the evolution of the unit cell volume with Fe concentration. The bottom graph shows the increase in $c$ and the decrease in $a$ lattice parameters with increasing Fe. Both graphs show the transition from tetragonal (T) to cubic (C) structures for $\mathrm{x}>0.25$.

Figure 3. Magnetic susceptibility vs. temperature for $\left(\mathrm{Cr}_{1-x} \mathrm{Fe}_{x}\right)_{2} \mathrm{Al}$ collected at $10^{3}$ or $10^{4}$ Oe; inset is enlarged view of $0 \leq x \leq 0.1$ showing the decrease in transition temperature with $x$.

Figure 4.Temperature-composition phase diagram of the $\left(\mathrm{Cr}_{1-x} \mathrm{Fe}_{\mathrm{x}}\right)_{2} \mathrm{Al}$ system.

Figure 5. Calculated non-magnetic densities of states for pure $\mathrm{Cr}, \mathrm{Cr}_{2} \mathrm{Al}$, and $\left(\mathrm{Cr}_{0.75} \mathrm{Fe}_{0.25}\right)_{2} \mathrm{Al}$ studied within the virtual crystal approximation.

Figure 6. The results of fixed-spin-moment calculations for supercell calculations of $\mathrm{Cr}_{3} \mathrm{FeAl}_{2}$ $\left(x=0.25\right.$ for $\left(\mathrm{Cr}_{1-x} \mathrm{Fe}_{x}\right) \mathrm{Al}$ and $\mathrm{Cr}_{3} \mathrm{Fe}\left(x=0.25\right.$ for $\left.\mathrm{Cr}_{1-\mathrm{x}} \mathrm{Fe}_{\mathrm{x}}\right)$. 

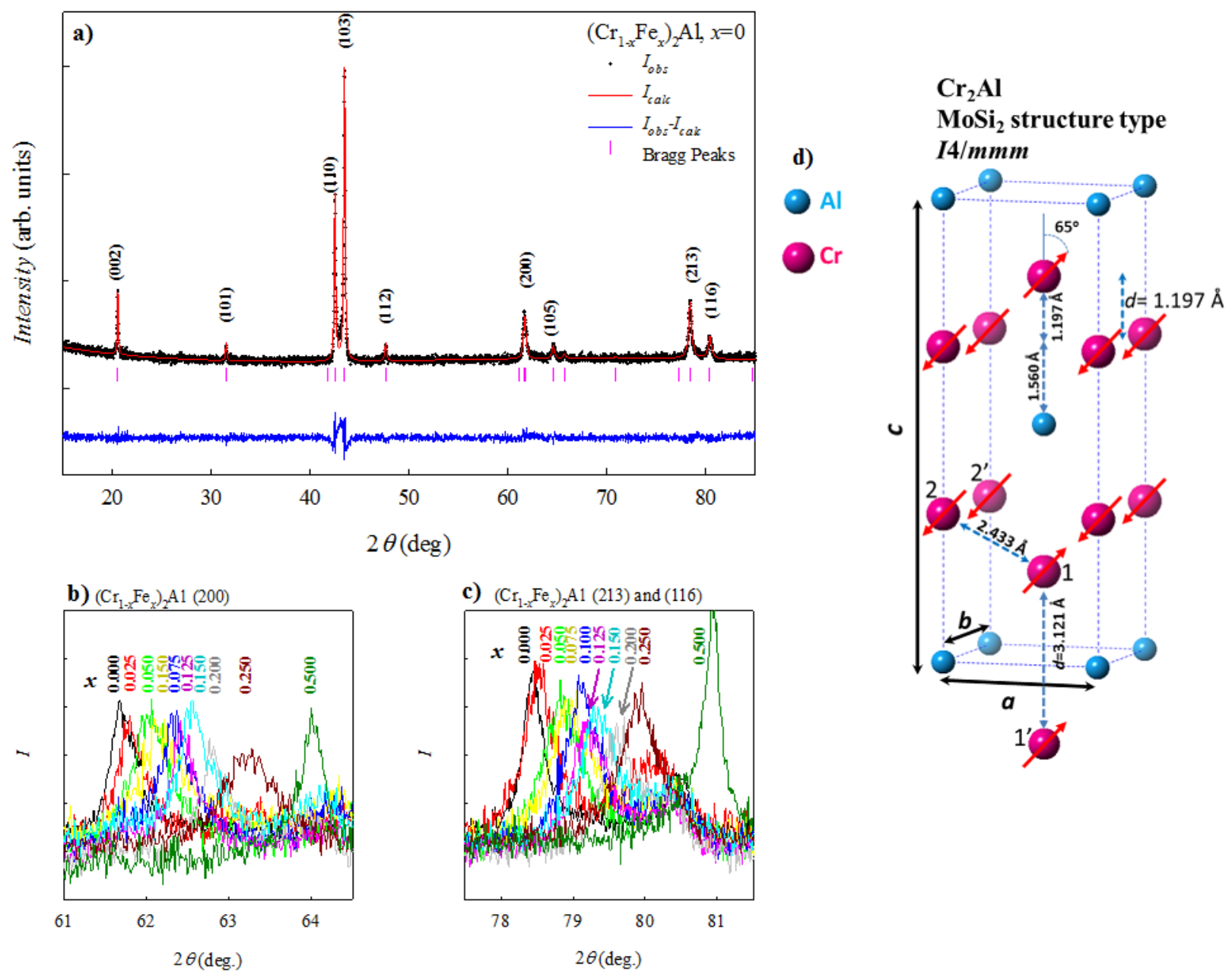

Figure 1. a) XRD pattern of $\left(\mathrm{Cr}_{1-x} \mathrm{Fe}_{x}\right)_{2} \mathrm{Al}, x=0.0$ showing experimental data, Rietveld refinement, and difference plot $\left(R_{w p}=7.30, R_{\text {exp }}=5.71\right)$; b) Expanded view of evolution of (200) peak reflection showing systematic peak shift to larger $2 \theta$ (i.e. smaller $d$ ) with increasing $\mathrm{Fe}$ substitution; c) Expanded view of (213) and (116) peak reflections showing the same; d) crystal structure of the parent compound $\mathrm{Cr}_{2} \mathrm{Al}$ with $\mathrm{Cr}-\mathrm{Cr}$ atomic plane separation distance and spin structure adapted from Kallel [14] and Atoji [12]. 

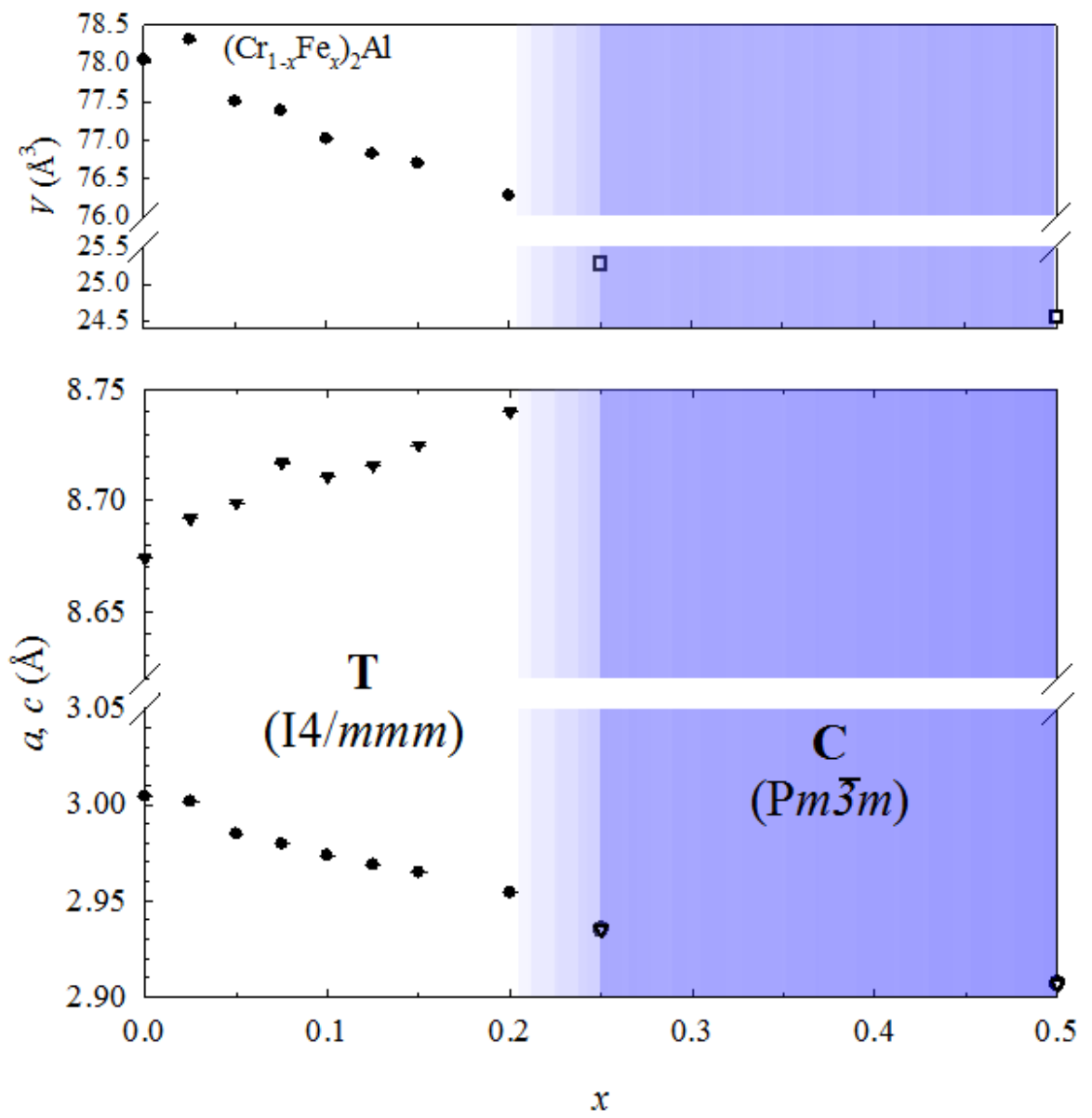

Figure 2. Evolution of $\left(\mathrm{Cr}_{1-\mathrm{x}} \mathrm{Fe}_{\mathrm{x}}\right)_{2} \mathrm{Al}$ with increasing Fe concentration. The top graph shows the evolution of the unit cell volume with Fe concentration. The bottom graph shows the increase in $c$ and the decrease in $a$ lattice parameters with increasing Fe. Both graphs show the transition from tetragonal (T) to cubic (C) structures for $\mathrm{x}>0.25$. 


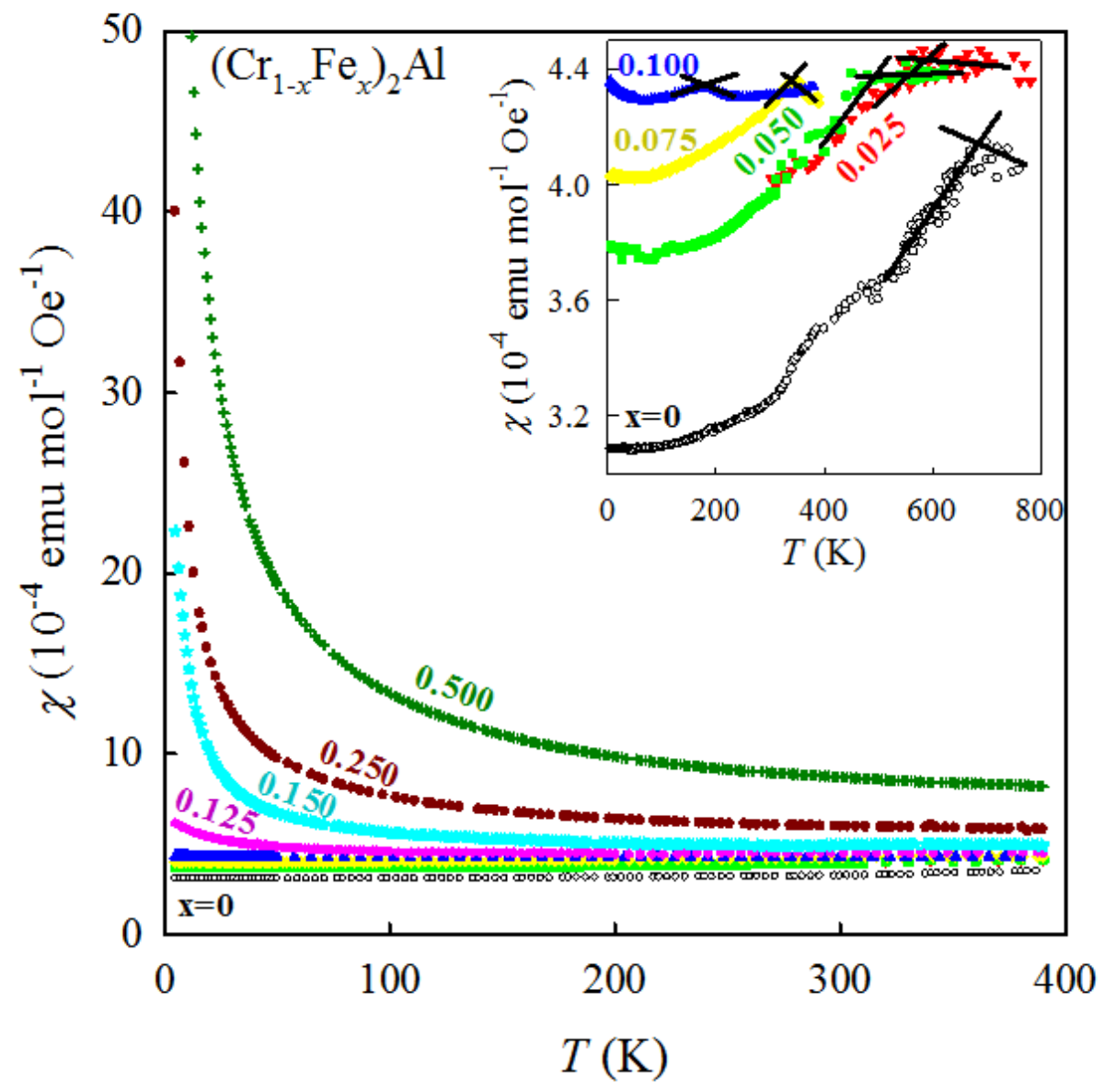

Figure 3. Magnetic susceptibility vs. temperature for $\left(\mathrm{Cr}_{1-x} \mathrm{Fe}_{x}\right)_{2} \mathrm{Al}$ collected at $10^{3}$ or $10^{4} \mathrm{Oe}$; inset is enlarged view of $0 \leq x \leq 0.1$ showing the decrease in transition temperature with $x$. 


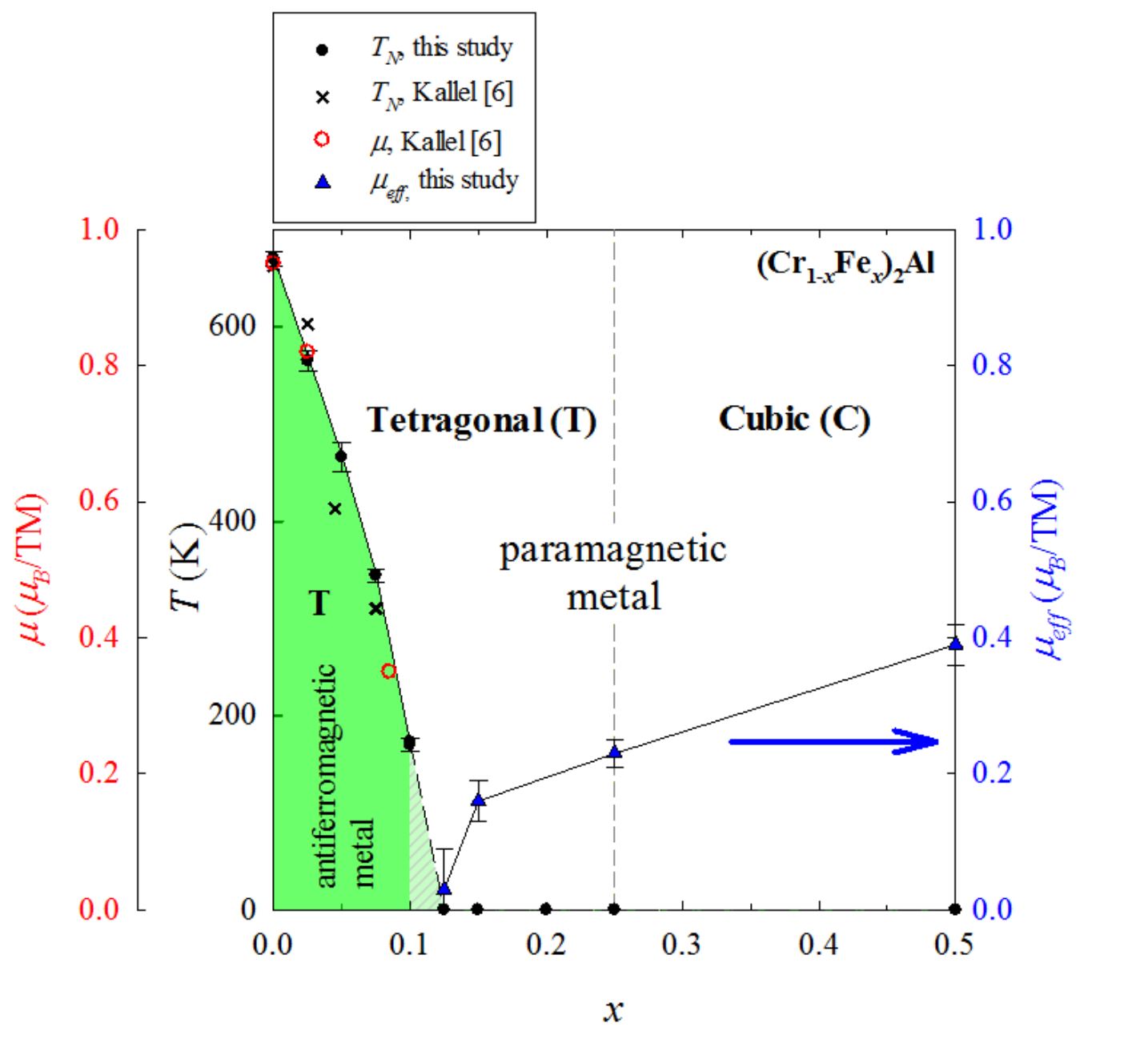

Figure 4.Temperature-composition phase diagram of the $\left(\mathrm{Cr}_{1-x} \mathrm{Fe}_{\mathrm{x}}\right)_{2} \mathrm{Al}$ system. 


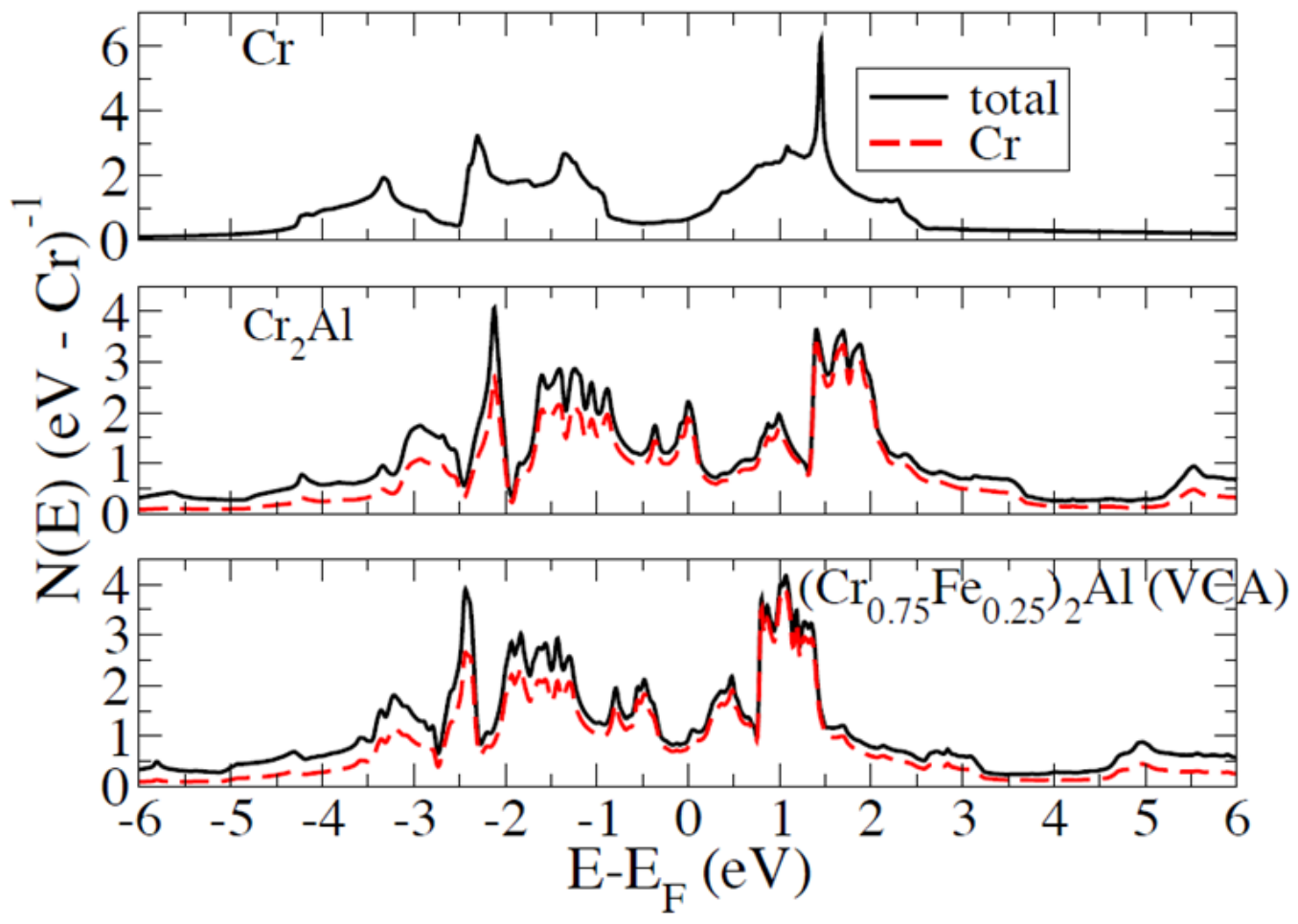

Figure 5. Calculated non-magnetic densities of states for pure $\mathrm{Cr}, \mathrm{Cr} 2 \mathrm{Al}$, and $\left(\mathrm{Cr}_{0.75} \mathrm{Fe}_{0.25}\right)_{2} \mathrm{Al}$ studied within the virtual crystal approximation. 


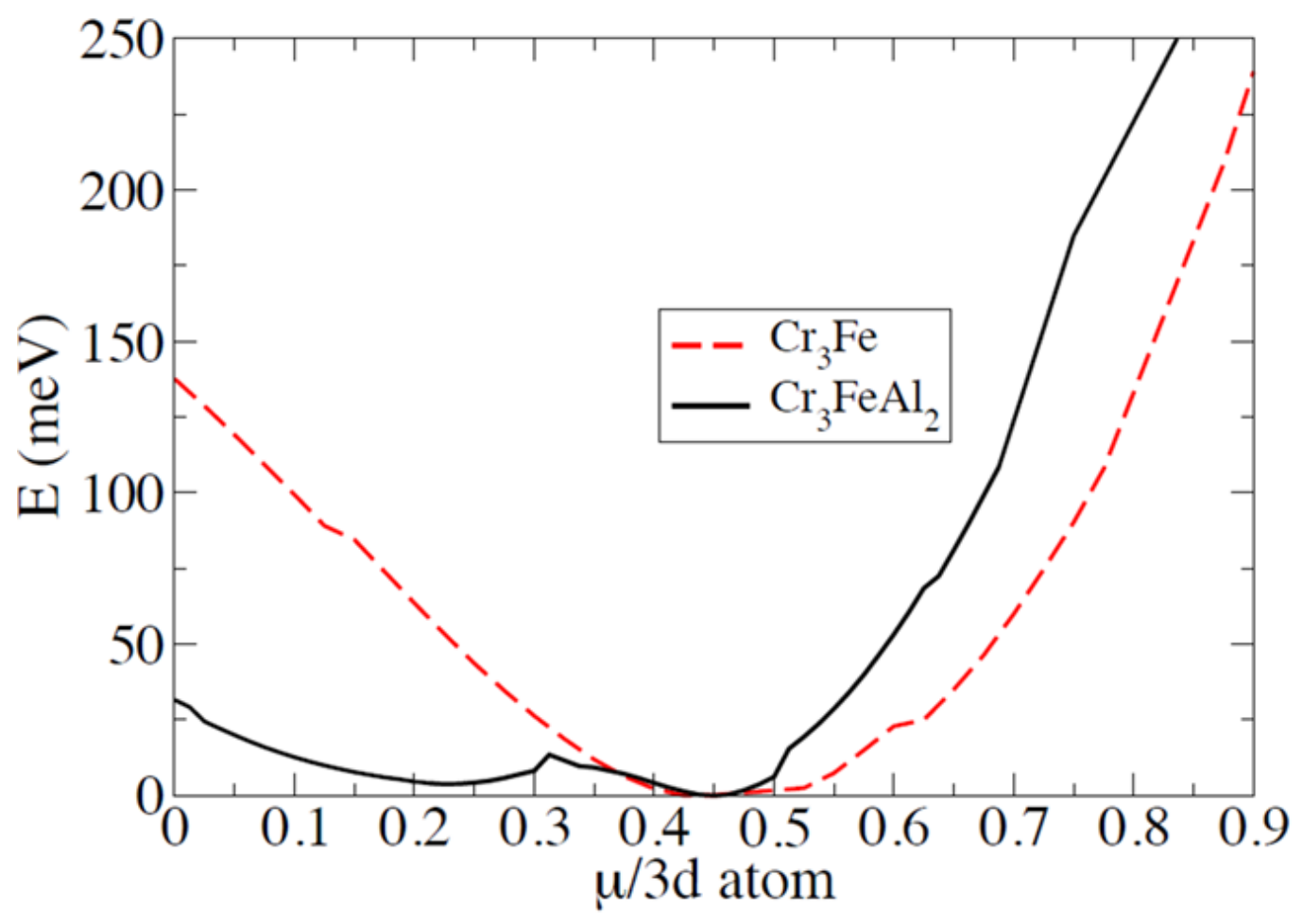

Figure 6. The results of fixed-spin-moment calculations for supercell calculations of $\mathrm{Cr}_{3} \mathrm{FeAl}_{2}(x=0.25$ for $\left(\mathrm{Cr}_{1-x} \mathrm{Fe}_{x}\right) \mathrm{Al}$ and $\mathrm{Cr}_{3} \mathrm{Fe}\left(x=0.25\right.$ for $\left.\mathrm{Cr}_{1-\mathrm{x}} \mathrm{Fe}_{\mathrm{x}}\right)$. 

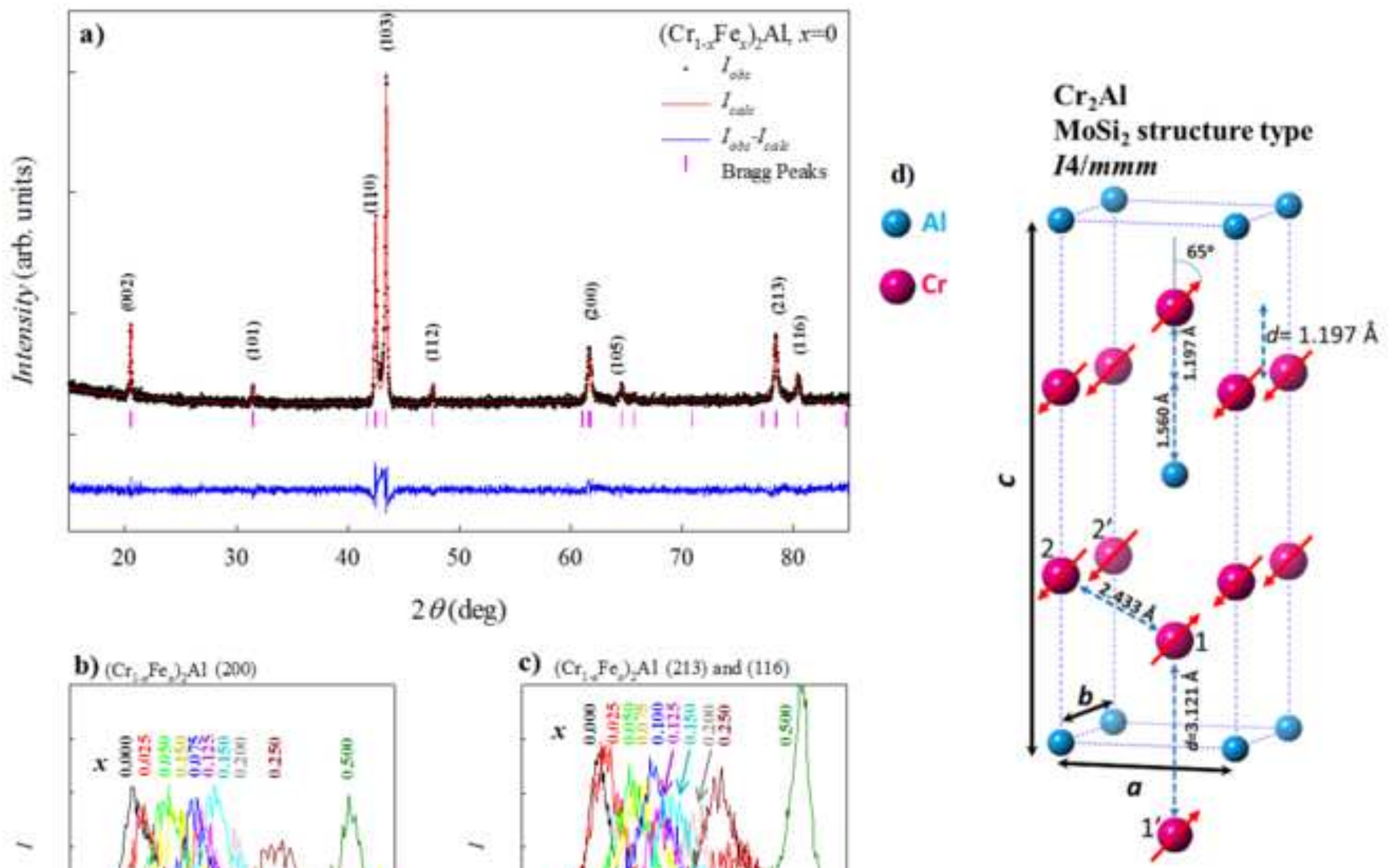

b) $(\mathrm{Cr}, \mathrm{Fe}, \mathrm{Al}(200)$

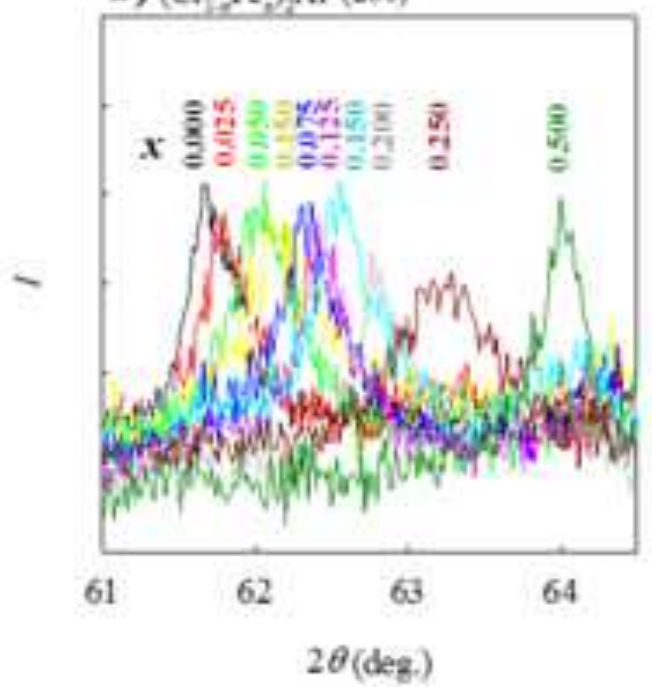

c) $\left(\mathrm{Cr}_{1}, \mathrm{Fe}\right)$, Al (213) and (116)

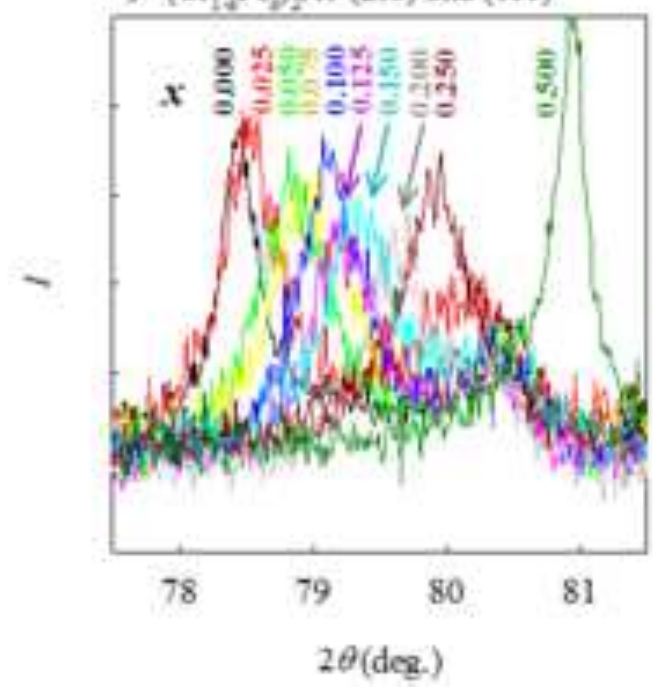

$\mathrm{Cr}_{2} \mathrm{Al}$

$\mathrm{MoSi}_{2}$ structure type

$14 / \mathrm{mmm}$

(2)

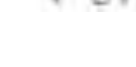



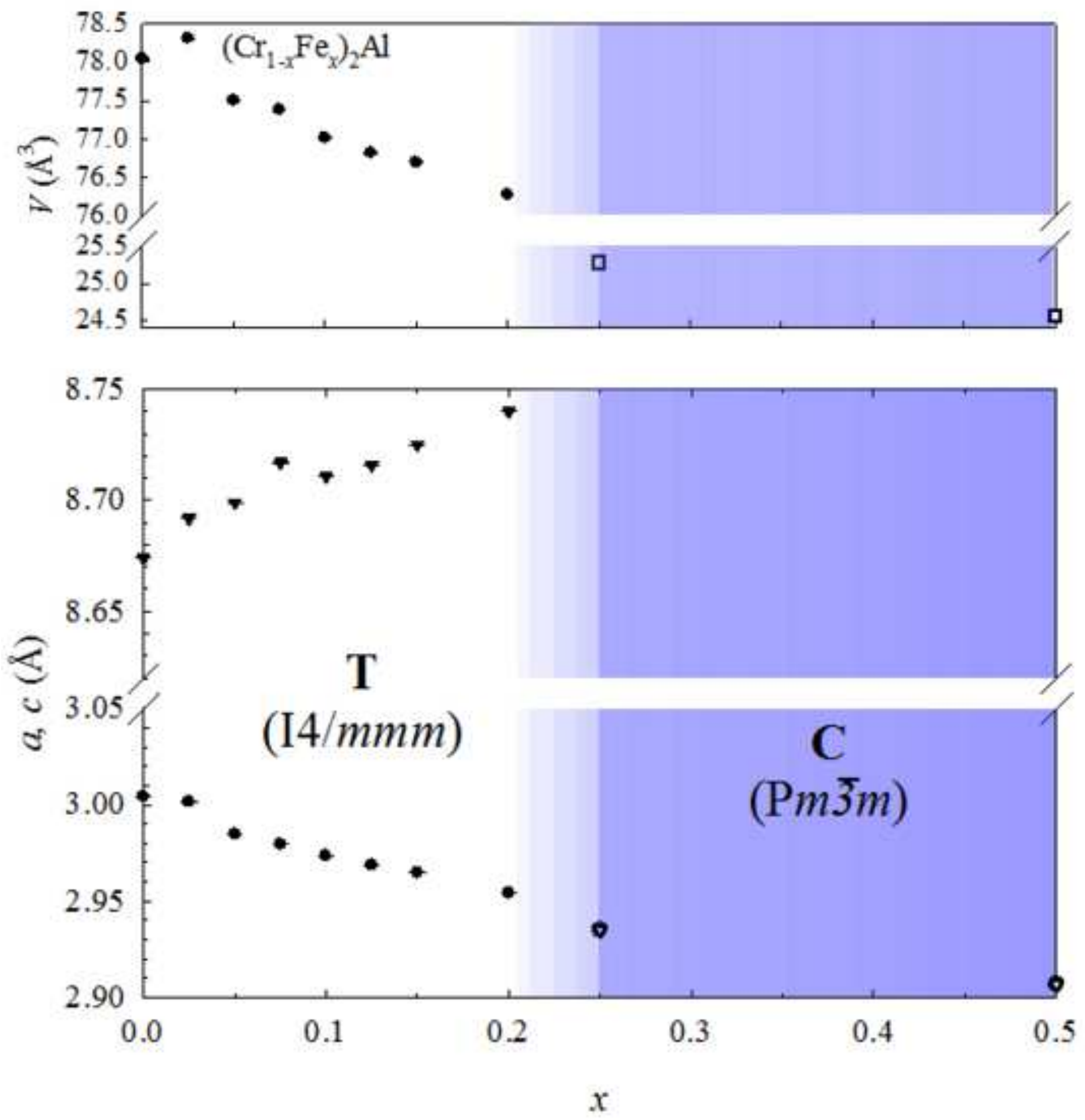

Figure 2 


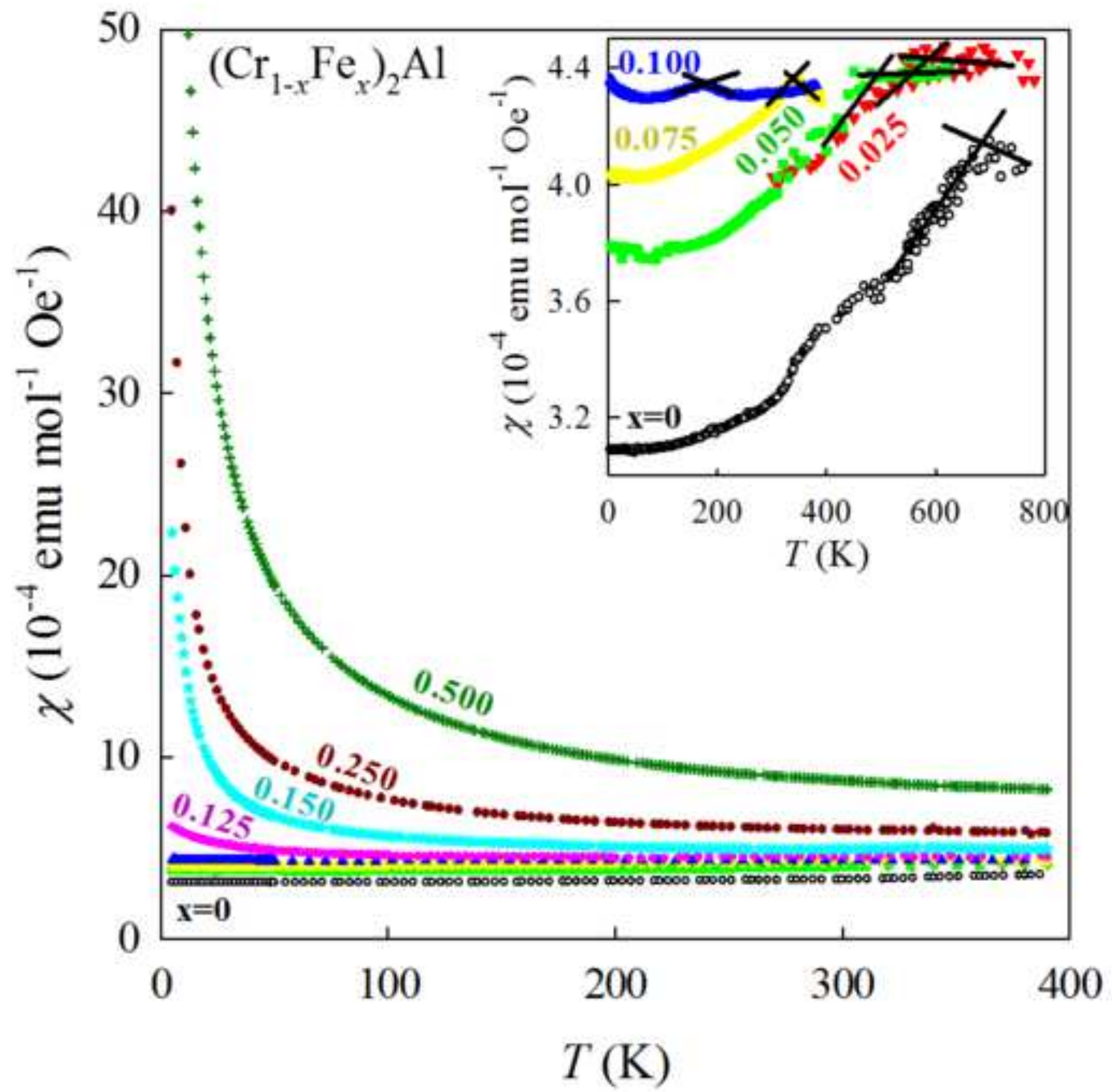




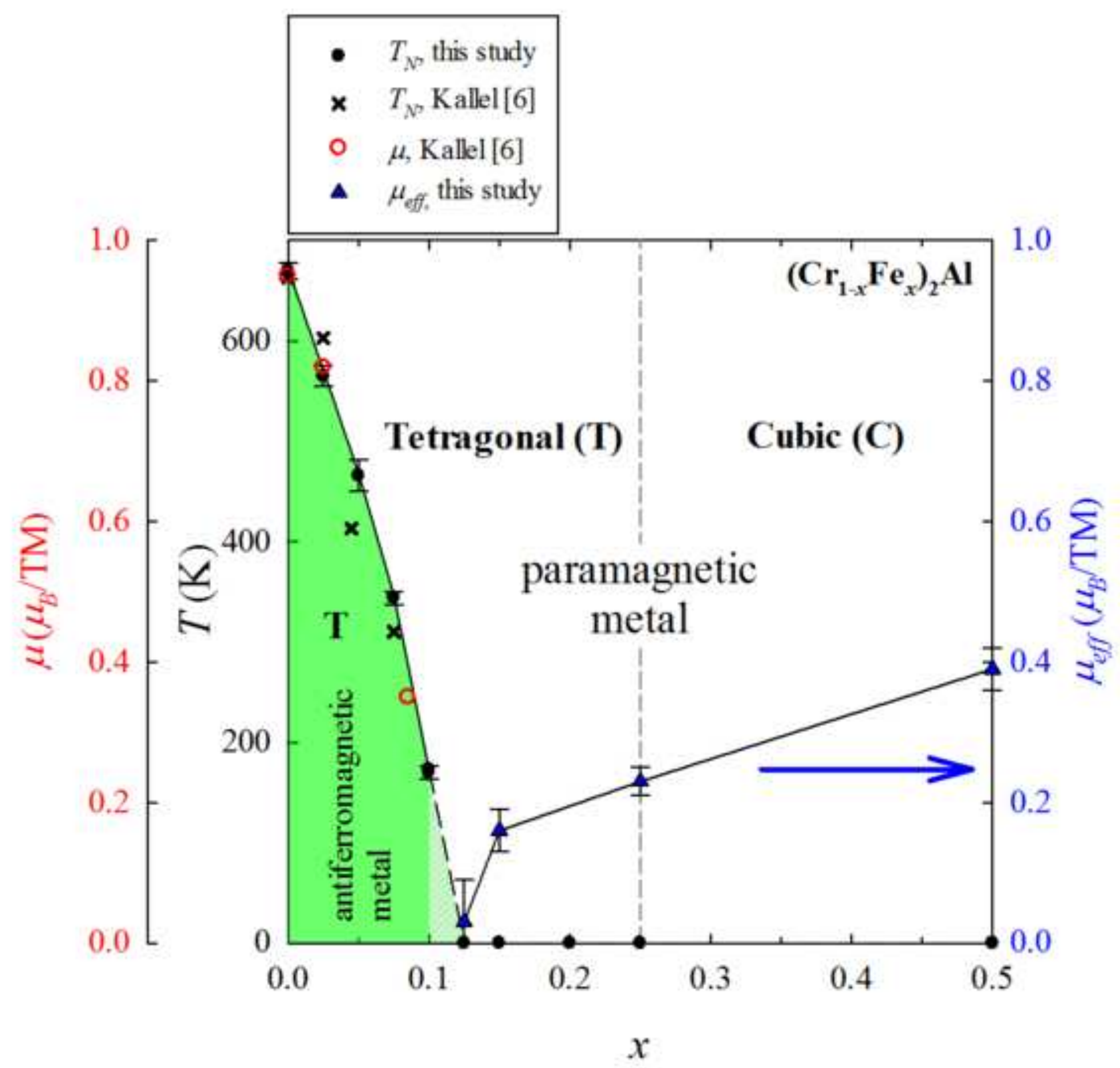




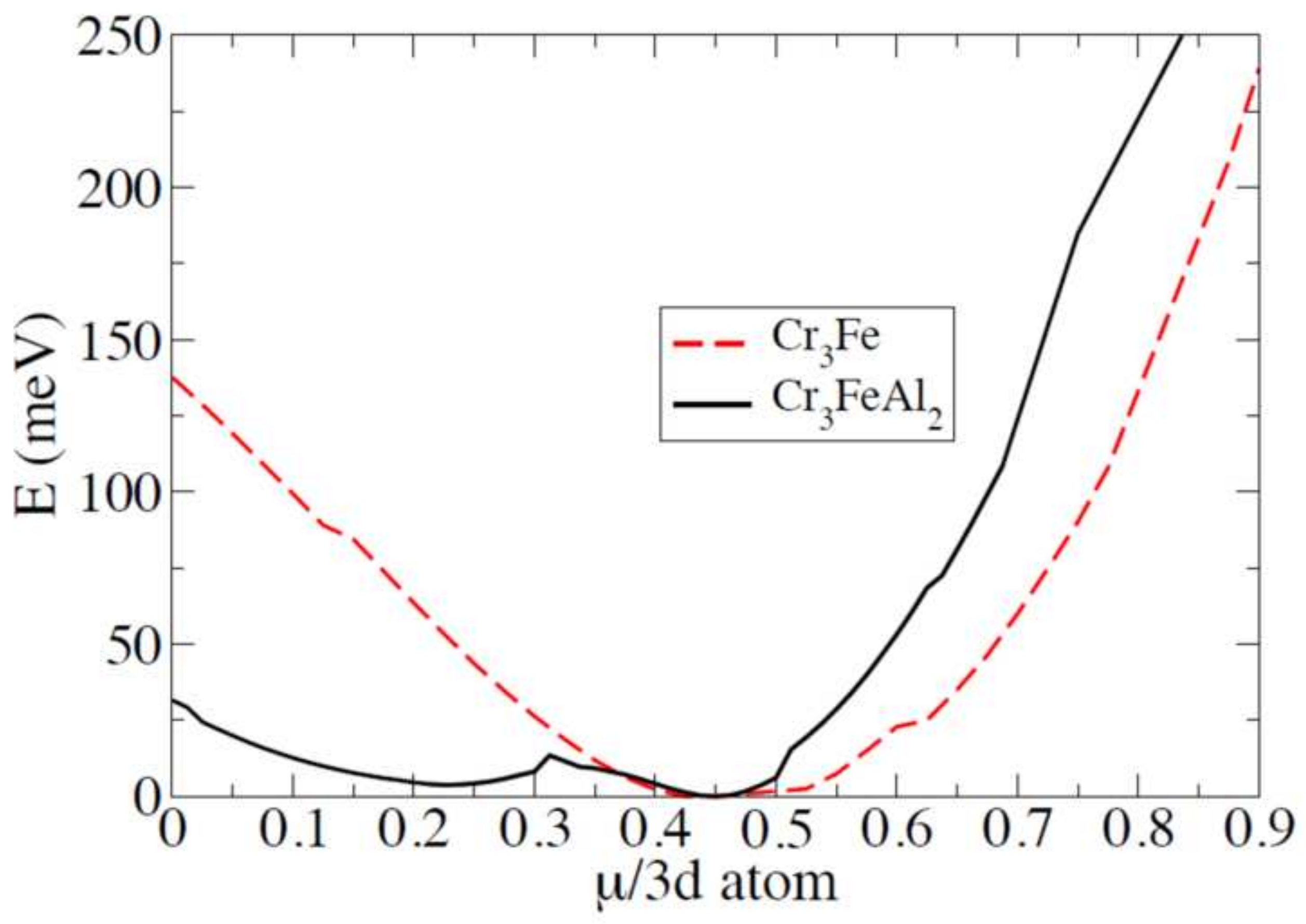

